\title{
The construction of authorial voice in writing research articles: A corpus-based study from an APPRAISAL theory perspective
}

\author{
WEIYU ZHANG \& YIN LING CHEUNG* \\ Nanyang Technological University (Singapore)
}

Received: 02/02/2018. Accepted: 05/10/2018.

\begin{abstract}
This study explores voice from an APPRAISAL theory perspective. It aims to investigate how published research writers deploy ATTITUDE and GRADUATION resources to review existing literature in the field. The study is based on a corpus of literature reviews (LRs) from 204 research articles (RAs) in computer networks and communications (CNC) and second language writing (SLW). Findings show that 1) writers demonstrate a strong preference to express their attitude through APPRECIATION rather than AFFECT and JUDGEMENT resources; 2) more FORCE than FOCUS resources are used to upgrade attitudinal meanings realized through ATTITUDE resources or to evoke APPRECIATION; and 3) one-way ANOVAs and post hoc tests have detected significant differences in the use of AFFECT and JUDGEMENT resources and in two sub-categories of FORCE and FOCUS resources. The study contributes to new knowledge by relating ATTITUDE and GRADUATION resources to the construction of voice in the disciplines of CNC and SLW.
\end{abstract}

KEYWORDS: Voice, second language writing, ATTITUDE, GRADUATION, APPRAISAL theory, research articles.

\section{INTRODUCTION}

The importance of voice has been increasingly recognized in the writing of effective academic texts and has become a central concept in the research of discourse, composition, and literature (Hyland, 2008; Hyland \& Guinda, 2012). Over the years, studies have explored voice in various types of texts from different perspectives, including "style" (Elbow, 1994), “individualism" (Remanathan \& Atkinson, 1999), "self-representation” (Ivanič \& Camps,

*Address for correspondence: Yin Ling Cheung. National Institute of Education, Nanyang Technological University, Singapore; e-mail: yinling.cheung@nie.edu.sg 
2001), "evaluation" (Thompson \& Hunston, 2000), “APPRAISAL" (Martin \& White, 2005), and "stance and engagement" (Hyland, 2005, 2008). More recently, there has been an important strand of research that has attempted to understand voice within the domain of interpersonal meaning (Cheung \& Low, 2017). From this perspective, voice refers to the expression of the writer's viewpoint in relation to readers as well as writing conventions and expectations of their discourse community (Hyland, 2008, 2012). Our study adopts this perspective of voice.

Existing studies seek to understand the construction of voice by analyzing linguistic and discursive features in various types of writings. An important focus of such studies is on research articles (RAs), a crucial way to transmit discipline knowledge, to understand disciplinary writing practices. For example, Chang and Schleppegrell (2011) analyzed introductions in RAs by published writers in the field of education. In light of the APPRAISAL framework, they have identified common linguistic patterns adopted by published research writers to effectively construct voice and shape powerful argument. The identified patterns were also found to be explicitly linked to the rhetorical purposes (Swales, 1990) in writing RAs. Other studies have detected meaningful variations of voice in RAs across disciplines. Hyland (2005, 2008), for example, examined a corpus of published RAs from 8 disciplines and discovered that writers from different disciplines construct their voice in different ways and the variations generally follow along the traditional "soft" and "hard" discipline lines. In comparison with Hyland's results, McGrath and Kuteeva (2012) found linguistic patterns specific to writers in the field of pure mathematics to construct their voice. According to interview data with the authors, these patterns can be attributed to the epistemology and research practices of the pure mathematics discipline and these published authors are conscious of the need to adhere to disciplinary writing conventions. Overall, these studies shed light on a rich set of linguistic and discursive resources to effectively construct voice and how voice in RAs is closely linked to the purposes of research writing as well as disciplinary conventions. The insights can serve as practical guidance for novice research writers who may struggle with the appropriate academic language to present a convincing argument and position their research properly in the ongoing discipline dialogue. The insights will be particularly helpful for English as Additional Language (EAL) research writers because the major obstacle for them to publish in prestigious English-medium journals is their unfamiliarity with their additional language and culturally different disciplinary conventions (Belcher, 2007; Cho, 2004; Flowerdew \& Wang, 2016).

Following this line of research, the current study explores voice in RAs published in peer-reviewed English-medium journals with international prestige to uncover linguistic patterns to realize voice by expert research writers. The focus of our exploration is on the literature review (LR) section, where the writers argue for the value and relevance of their own research through a critical review of related literature. Existing evidence suggests that 
LR is among the most difficult sections to write for novice researchers, especially those from EAL background (e.g., Uzuner, 2008). Studies have probed into the features of LRs from various perspectives to inform teaching and learning. For example, the study by Kwan, Chan, and Lam (2012) has identified useful evaluation strategies in journal article LRs based on the CARS model (Swales, 1990). And the distribution of the strategies demonstrates a clear distinction between two research paradigms of Information Systems. Their findings, however, are restricted to the propositional content of LRs, without offering any helpful implications at the linguistic level for EAL writers in particular. Gil-Simon and SolerMonreal (2014) took a step forward and explored the linguistic resources to realize rhetorical moves of LRs in PhD theses. Although it offered insights on the potential linguistic resources that EAL writers can draw upon, their study is limited by the small sample size $(\mathrm{N}=20)$ from one single subject area and may impede quantitative generalization.

Building on this body of research, the current study aims to make the potential linguistic resources explicit to construct an appropriate voice in achieving the rhetorical goals of LRs while complying with the writing conventions of disciplines and research paradigms. The study is guided by the ATTITUDE and GRADUATION frameworks, which alongside with ENGAGEMENT form the larger system of APPRAISAL in Systemic Functional Linguistics (SFL). The system of APPRAISAL has informed many studies of voice, which have yielded useful implications. For example, Humphrey and Hao (2013) have examined key academic genres of undergraduate biology and reported on the interplay of APPRAISAL resources in achieving the rhetorical goals of the target genres. Their findings shed light on a repertoire of linguistic resources for novice undergraduates to control key genres. However, like many other studies applying APPRAISAL in academic writing context (Lancaster, 2014; Miller, Mitchell \& Pessoa, 2014; Wu, 2007), the focus of the study is on student writing, rather than on RAs (Chang \& Schleppegrell, 2011; Zhang \& Cheung, 2017). And many of the studies favor the ENGAGEMENT framework, rather than ATTITUDE and GRADUATION (except for Cheung \& Low, 2017, Hood, 2004; Lee, 2015). To the best of our knowledge, there has been no study so far that adopts the ATTITUDE and GRADUATION frameworks to study LRs. To fill the research gaps, the current study seeks to explore how the two frameworks may provide useful insights on voice construction in LRs. The exploration will be based on a much larger sample size of 204 to enable a more confident quantitative generalization.

Moreover, as evidence suggests that meaningful variations in writing not only exist across disciplines, but also across sub-disciplines and research paradigms (Cao \& $\mathrm{Hu}, 2014$; Ozturk, 2007), the current study also tries to uncover possible variations of voice between two sub-disciplines of computer network and communication (CNC) and second language writing (SLW). The chosen sub-disciplines were from the larger discipline area of computer science and applied linguistics, representing both "hard" and "soft" disciplines. The two 
different research paradigms (i.e., qualitative and quantitative) in SLW will also be explored separately to see whether variation exists.

The current study is guided by the two research questions below:

1. Is there any common pattern of voice realized through ATTITUDE and GRADUATION resources among the three types of LRs (i.e., CNC, qualitative SLW, and quantitative SLW)? If so, how?

2. Is there any variation of voice realized through ATTITUDE and GRADUATION resources among the three types of LRs? If so, how?

\section{ANALYTICAL FRAMEWORK}

The analysis of ATTITUDE and GRADUATION resources is conducted with reference to the most comprehensive description of the APPRAISAL system to date, by Martin and White (2005). According to the framework, ATTITUDE comprises three complementing subsystems, namely, AFFECT, JUDGEMENT, and APPRECIATION. AFFECT deals with our positive and negative feelings or emotional reactions. JUDGEMENT involves evaluations of human behaviors. APPRECIATION is concerned with assessing the value of things or phenomena. Within the sub-system of AFFECT, emotions are further grouped into three major sorts of 'un/happiness', 'in/security' and 'dis/satisfaction'. The 'un/happiness' sort has to do with feelings of happy or sad, and affection (liking) or antipathy (disliking). The 'in/security' sort deals with feelings related to peace, anxiety, fear, confidence and trust. The 'dis/satisfaction' sort comprises feelings of interest or pleasure towards the activities we are engaged in. Within the sub-system of JUDGEMENT, people's behaviors are evaluated in terms of their 'normality' (how special someone is), 'capacity' (how capable someone is), 'tenacity' (how dependable or determined someone is), 'veracity' (how honest someone is) and 'property' (how moral and ethical someone is). Within the sub-system of APPRECIATION, the value of things or phenomena can be assessed by our 'reaction' (how we appreciate their quality or what impact they have on us), their 'composition' (balance and complexity) and their 'valuation' (social desirability, significance, reliability, etc.). See Figure 1 for an illustration of the hierarchical relationship among the categories of ATTITUDE resources.

GRADUATION concerns the upgrading and downgrading of attitudinal meanings or assertions. According to the framework, attitudinal meanings and assertions can be graded according to two axes: FORCE and FOCUS. FORCE refers to GRADUATION by reference to the degree of 'intensity', 'amount' and 'extent'. The scaling of 'intensity' is termed INTENSIFICATION and applies to qualities (e.g., particularly useful), processes (e.g., 
greatly enhances) and also to modalities (e.g., quite often) (all examples given are from the corpus of the current study.) The scaling of 'amount' and 'extent' is termed QUANTIFICATION and operates over entities. It provides imprecise measurement of 'number' (e.g. a substantial number of studies), 'mass/presence' of entities according to their size or weight (e.g., a considerable gap), 'extent' of entities according to distribution (e.g., across all disciplines, a long history of such practice) or proximity (e.g., a recent experimental study). FOCUS refers to GRADUATION by reference to prototype or the degree to which something or a phenomenon matches a semantic category (e.g., truly longitudinal data). The use of FOCUS carries the rhetorical effect of either 'sharpening' (e.g., truly) or 'softening' (e.g., in abstractly academic way) of meanings according to the degree of match or authenticity. Following the practice of Hood and Martin (2007), we extend the FOCUS category to include resources that 'sharpen' or 'soften' meanings according to the degree of specificity (e.g., especially in the physical sciences; the general category of). See Figure 2 for an illustration of the hierarchical relationship among the categories of GRADUATION resources.

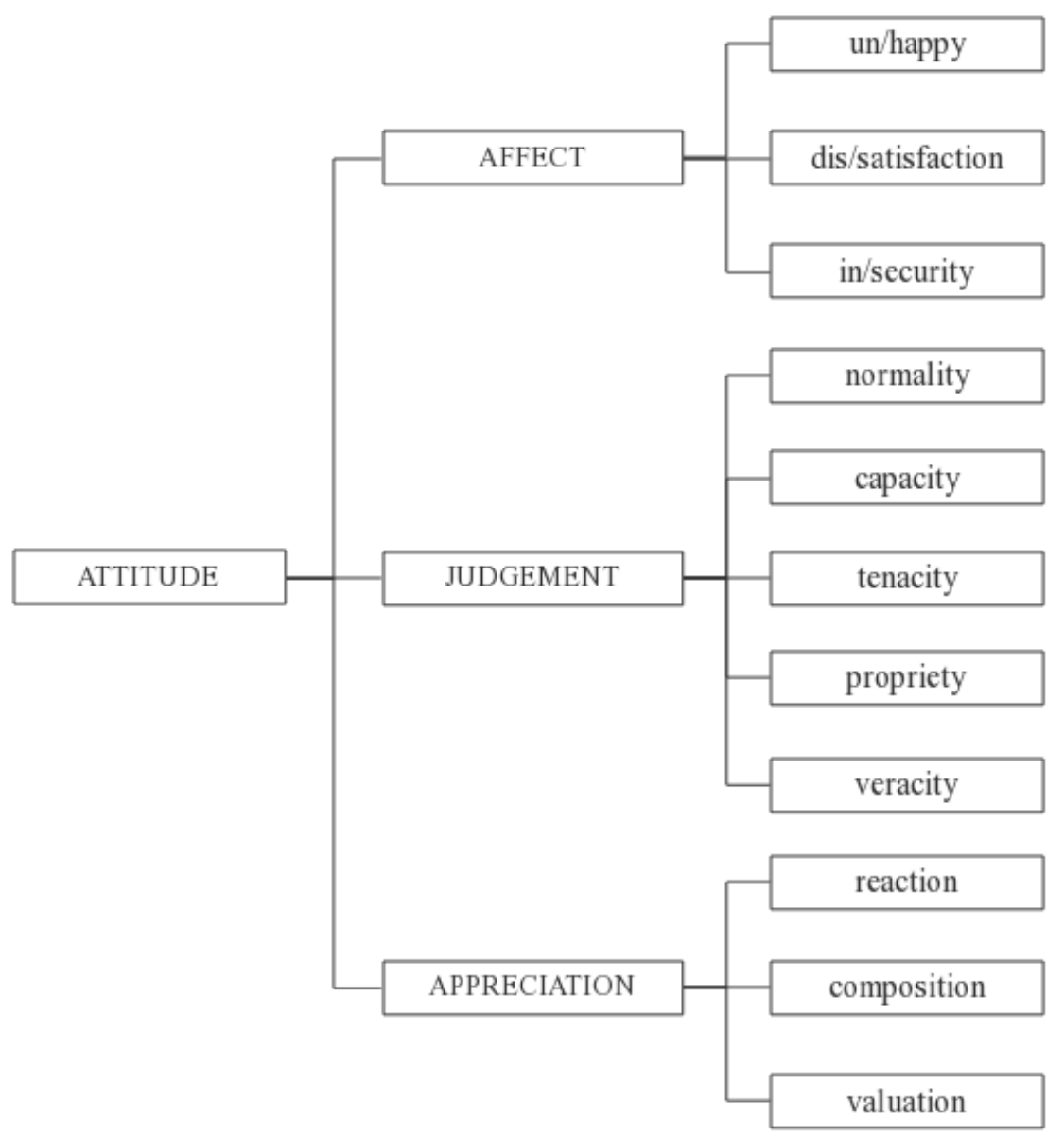

Figure 1. The ATTITUDE framework. 


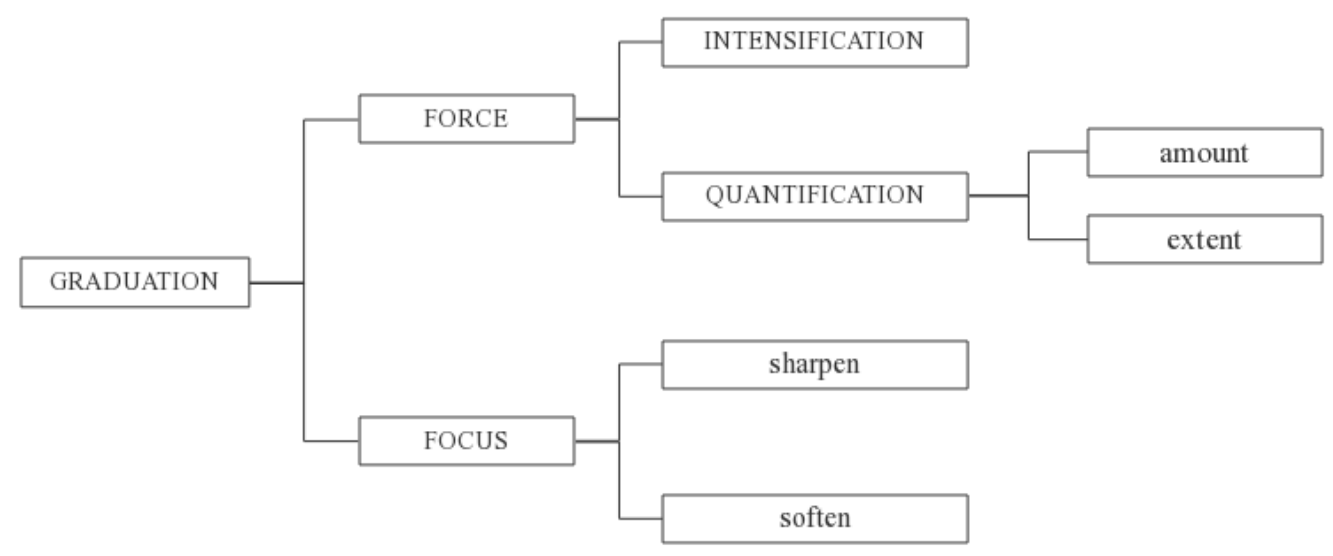

Figure 2. The GRADUATION framework.

GRADUATION resources can be used to upgrade or downgrade the attitudinal meanings realized through ATTITUDE resources e.g., particularly (FORCE) useful (APPRECIATION) and also to evoke positive and negative APPRECIATION (Hood, 2004). Examples of evoked APPRECIATION through GRADUATION resources will be illustrated in the "Results" section.

\section{METHODOLOGY}

\subsection{Corpus}

To explore the research questions, a corpus consisting of 68 qualitative SLW, 68 quantitative SLW, and 68 CNC LRs was built. Compared to other studies exploring the use of ATTITUDE and GRADUATION in academic writing context (Hood, 2004; Lee, 2015), the corpus of current study contains a much larger number of writing samples. This allows a more confident quantitative generalization of the findings within the two sub-disciplines under exploration. All the LRs were extracted from empirical RAs published from 2011 to 2015 in internationally prestigious peer-reviewed English-medium journals. The SLW LRs come from 6 SSCI journals, namely, Journal of Second Language Writing, English for Specific Purposes, Language Learning and Teaching, Journal of English for Academic Purposes, Computer Assisted Language Learning, and System. The selection was based on the rankings of applied linguistics journals in Journal Citation Report (2015) by Thomson Reuters. However, some journals such as Applied Linguistics may have a higher ranking but was not selected due to the fact that there are fewer than five articles on the topic of SLW published during the five-year period. In total, we have identified 68 quantitative and 100 qualitative RAs from the six journals following the classification offered by Creswell (2009). 
Mixed-method studies were not concerned in the current exploration and thus not counted. We kept all the 68 quantitative RAs and used computer-generated random numbers to select 68 qualitative ones to keep the number of samples equal. Similarly, the 68 CNC RAs come from three CNC journals, namely, IEEE Transactions on Computers, IEEE-ACM Transaction on Networking and IEEE Transactions on Mobile Computing. The journals were selected based on Scimago Journal and Country Rank (2015). The LR sections were then extracted from each article. LR usually locates between introduction and methodology, titled "literature review" in SLW or "related literature" in CNC papers. Nonetheless, it may not always have an explicit title and sometimes may be integrated into introduction or even placed at the end of some CNC RAs. For those exceptional cases, we manually identified the section by reference to the three rhetorical moves in writing LRs: 1) establishing a territory; 2) establishing a niche; 3) occupying the niche (Swale, 1990). The LRs were then converted into plain text for data coding (See Table 1 for descriptive statistics of the corpus).

\begin{tabular}{lccc}
\hline & $\begin{array}{c}\text { Qualitative } \\
\text { SLW }\end{array}$ & $\begin{array}{c}\text { Quantitative } \\
\text { SLW }\end{array}$ & CNC \\
\hline No. of LRs & 68 & 68 & 68 \\
Total no. of words & 80867 & 106181 & 39806 \\
Mean no. of words & 1189 & 1561 & 585 \\
\hline
\end{tabular}

Table 1. Descriptive statistics of the corpus.

\subsection{Data coding}

Data coding was done with UAM Corpus Tool (O'Donnell, 2011) at two levels. At the first level, each LR was coded according to its source (i.e., CNC, qualitative SLW, and quantitative SLW). At the second level, ATTITUDE and GRADUATION resources in the LRs were identified and coded according to their categories (e.g., AFFECT). The coding of ATTITUDE and GRADUATION resources requires a good understanding of the frameworks as well as careful consideration of meaning in context, which could be subjective and inconsistent. To mitigate the subjectivity and inconsistency, inter- and intra-coder agreement measures have been adopted. For inter-coder agreement, we used peer-coding. A peer coder with an MA degree in applied linguistics was invited to be a second coder. The first-author, also the first coder, held some sessions with the second coder to standardize the two coders' understanding of the frameworks. Then the two coders separately coded some portion of the data and then compared to resolve differences. At last, the two coders coded another three percent of the data separately and the agreement rate assessed by Cohen's Kappa was at .827 for ATTITUDE and .870 for GRADUATION. As the agreement rate was satisfactory, the 
first coder continued to code all the remaining data alone. For intra-code agreement measure, the first coder coded all the data twice at different sittings. Then all coded categories were carefully examined to guarantee consistency.

\subsection{Data analysis}

We adopted both quantitative and qualitative means to analyze our data. For quantitative analysis, the mean frequency of ATTITUDE and GRADUATION resources identified in the corpus was calculated and normalized per 1000 words. One-way ANOVAs and post hoc tests were run to determine whether a significant difference exists in the use of ATTITUDE and GRADUATION resources among the three groups. The alpha value was set at .05 . When a significant difference was detected, eta squared was used to calculate the effect size. For qualitative analysis, all the coded instances were carefully considered in context to see whether there was a meaningful pattern in the use ATTITUDE and GRADUATION resources to fulfill the goals of writing LR.

\section{RESULTS}

\subsection{Summary of quantitative findings}

The descriptive statistics of both ATTITUDE and GRADUATION resources identified in our corpus are presented in Table 2. The results of one-way ANOVAs and post hoc texts reveal both common patterns and variations of voice among the three groups of writers.

In terms of common patterns, the three groups of writers demonstrate a similar general trend in their deployments of both ATTITUDE and GRADUATION resources. To start with, all three groups of writers display a strong preference to express their ATTITUDE through APPRECIATION rather than AFFECT and JUDGEMENT resources (see Figure 3). Secondly, within the APPRECIATION category, all three groups of writers employ "valuation" resources predominantly more frequently than the rest two subcategories of "reaction" and "composition" (see Figure 4). The results of one-way ANOVAs, F (2, 201) = $.19, \mathrm{P}>.05$ for "reaction", $\mathrm{F}(2,201)=.88, \mathrm{P}>.05$ for "composition", and F $(2,201)=4.29$, $\mathrm{P}>.05$ for "valuation", indicate that there is no statistically significant difference in the use of these resources among the three groups. Thirdly, predominantly more FORCE than FOCUS resources are used by all three groups (see Figure 5). Under the category of FORCE, the results of one-way ANOVAs show that the three groups do not differ significantly from each other in the use of INTENSIFICATION, F $(2,201)=1.06, \mathrm{P}>.05$; nor do they differ in the use of the "amount" subcategory of QUANTIFICATION, F $(2,201)=.21, \mathrm{P}>.05$. Last 
but not least, no significant difference was detected in the use of the "soften" subcategory of FOCUS, F $(2,201)=.54, \mathrm{P}>.05$.

\begin{tabular}{lcccccc}
\hline & \multicolumn{3}{c}{ Qualitative SLW } & \multicolumn{2}{c}{ Quantitative } & \multicolumn{2}{c}{ CNC } \\
& Mean & SD & Mean & SD & Mean & SD \\
\hline ATTITUDE & 15.24 & 5.57 & 13.64 & 5.10 & 14.61 & 6.33 \\
AFFECT & 1.21 & 1.48 & .79 & 1.37 & .05 & .22 \\
JUDGEMENT & 1.27 & 1.96 & .65 & .88 & .22 & .60 \\
APPRECIATION & 12.77 & 4.55 & 12.20 & 4.51 & 14.34 & 6.30 \\
- reaction & 1.72 & 1.52 & 1.56 & 1.17 & 1.63 & 1.78 \\
- composition & .59 & 1.10 & .43 & .64 & .42 & .83 \\
- social valuation & 10.45 & 3.75 & 10.21 & 3.96 & 12.29 & 5.67 \\
\hline GRADUATION & 10.88 & 4.87 & 9.84 & 4.21 & 11.06 & 5.67 \\
FORCE & 9.91 & 4.59 & 9.09 & 3.98 & 10.44 & 5.21 \\
INTENSIFICATION & 5.16 & 2.99 & 4.50 & 2.28 & 4.96 & 2.82 \\
QUANTIFICATION & 4.75 & 2.68 & 4.59 & 2.50 & 5.47 & 3.99 \\
- amount & 3.56 & 2.19 & 3.38 & 1.89 & 3.63 & 2.85 \\
- extent & 1.19 & 1.12 & 1.20 & 1,03 & 1.84 & 1.75 \\
FOCUS & .97 & .88 & .75 & .79 & .62 & 1.15 \\
- sharpen & .82 & .78 & .65 & .73 & .45 & .88 \\
- soften & .15 & .38 & .10 & .28 & .17 & .54 \\
\hline
\end{tabular}

Table 2. Descriptive statistics of ATTITUDE resources in LRs.

In terms of variations, statistical tests reveal more significant differences between CS and SLW writers rather than between the qualitative and quantitative SLW writers. For example, the results of one-way ANOVAs, F $(2,201)=17.09, \mathrm{P}<.05$ for AFFECT, and $\mathrm{F}$ $(2,201)=11.34, \mathrm{P}<.05$ for JUDGEMENT, and post hoc tests suggest that the CNC writers utilize both resources significantly less frequently than SLW writers, whereas the SLW groups do not differ from each other. The effect size (eta squared $=.15$ ) is large for AFFECT and moderate (eta squared $=.10$ ) for JUDGEMENT. For the "extent" subcategory of QUANTIFICATION, the CNC writers employ significantly more such resources, whereas the SLW groups do not differ from each other. The effect size (eta squared $=.05$ ) is small. To further understand the difference about the subcategory of "extent", we carefully examined the coded instances in their context. We found that "extent" resources in CNC LRs are more frequently used to refer to the proximity in time $(\mathrm{M}=1.16, \mathrm{SD}=1.35)$ than in the qualitative 
SLW $(\mathrm{M}=.61, \mathrm{SD}=.83)$ and quantitative SLW LRs $(\mathrm{M}=.70, \mathrm{SD}=.83)$. Moreover, significantly more resources in the sub-category of "sharpen" are deployed by qualitative SLW writers than their CNC counterparts, F $(2,201)=3.79, \mathrm{P}<.05$. The effect size (eta squared $=.04)$ is small. However, there is no significant difference between the two SLW groups; nor between the CNC and quantitative SLW writers.

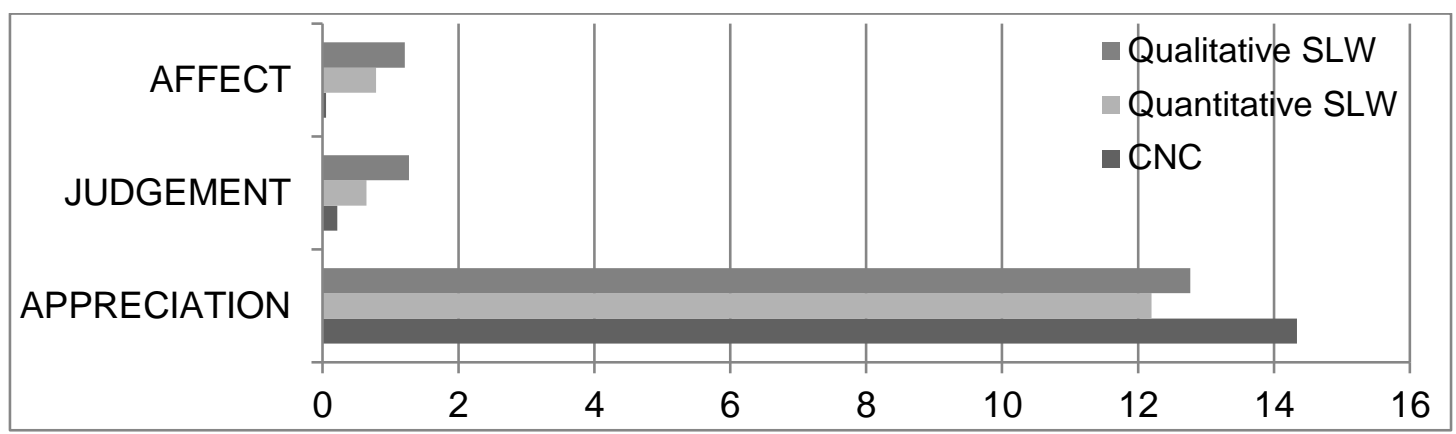

Figure 3. Distribution of ATTITUDE resources across three types of LRs.

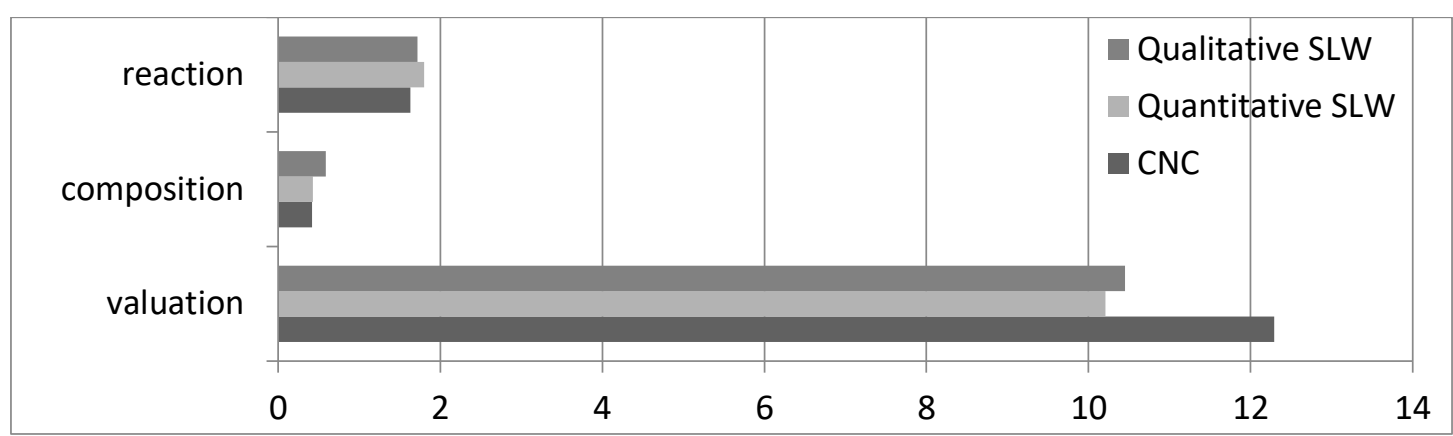

Figure 4. Distribution of the sub-categories of APPRECIATION resources across three types of LRs.

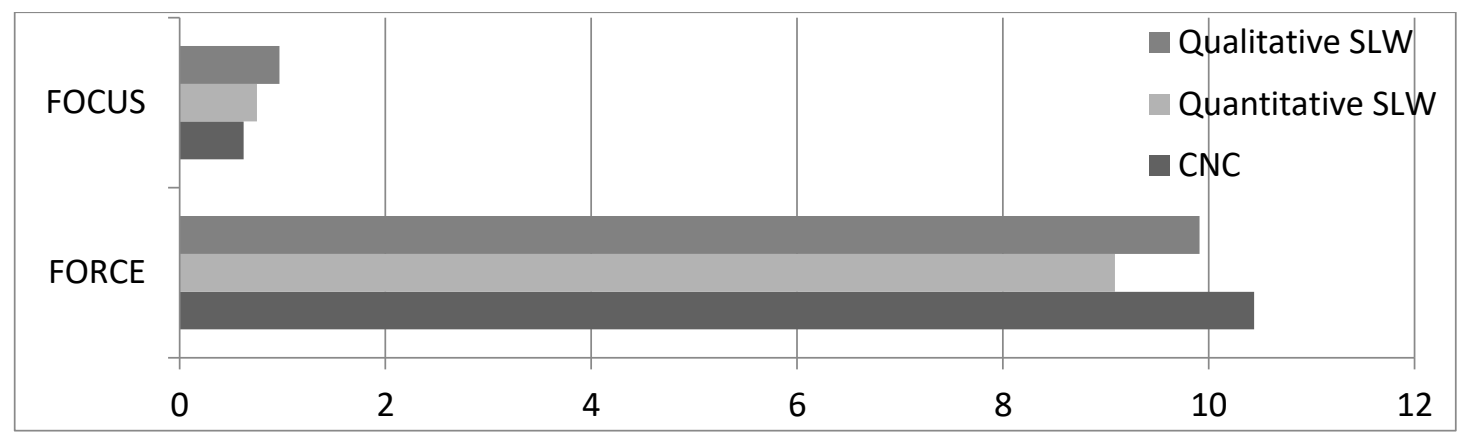

Figure 5. Distribution of GRADUATION resources across three types of LRs. 


\subsection{Summary of qualitative findings}

\subsubsection{Common patterns of voice}

Despite the variations detected by statistical tests, all three groups of writers demonstrate a similar general trend in their use of both ATTRIBUTE and GRADUATION resources. For example, all of them predominantly prefer the use of the "valuation" subcategory of APPRECIATION among all other ATTITUDE resources and rely more heavily on FORCE rather than FOCUS resources. The findings of similarities are not surprising as the LRs under study are from the same register of journal article and serve the common goal to establish the value of one's own study through a review of existing literature. A careful scrutiny of the identified resources in context allows us to identify common patterns of ATTITUDE and GRADUATION deployed by all three groups of writers to achieve their goal. The identified patterns can be clearly linked to the three rhetorical purposes proposed by Swales (1990): 1) establishing a territory; 2) establishing a niche; 3) occupying the niche. Now let us consider examples from the corpus to see how the three groups of expert writers maneuver linguistic resources to achieve the rhetorical purposes in LR. In the examples, the identified resources will be highlighted in bold and the categories where they belong will be specified in brackets.

\subsection{1.a. Establishing a territory}

To establish a territory, writers need to argue that the topic of their study is of value and worthy of research attention. A common strategy is to describe and positively appraise the research topic. This could be achieved through explicit ATTITUDE, usually the use of APPRECIATION coupled with GRADUATION. The use of GRADUATION can either grade attitudes or to evoke APPRECIATION. As in example [1], the paper reports on a performance study of error checking scheme for IEEE 802.16 based network. To argue for the value of the study, the writers point out the appealing quality of the IEEE 802.16 network through the use of an APPRECIATION resource "attractive", which is upgraded by two GRADUATION resources "recent" and "widely". The word "recent" suggests "a close in time from the present" and upgrades the APPRECIATION by stressing its proximity and immediate relevance to the current work. It also evokes a positive APPRECIATION of the research topic because the value of the topic would be diminished if IEEE 802.16 was "attractive" "many years ago" rather than in "recent years". The other GRADUATION resource "widely" upgrades the APPRECIATION by referring to the broad extent of the network's application. It also evokes a positive APPRECIATION of the research topic since the topic is relevant to a large number of geographical contexts.

[1] Recent [FORCE: QUAN: extent] years, IEEE 802.16 network (also named WiMAX network) is one of the attractive [ATT: APP: reaction] wireless transmission technologies. ... Some of them have been widely [FORCE: QUAN: extent] 
implemented and employed in some countries and areas to provide fixed and mobile wireless communications. (CNC 08)

The research topic could also be appraised negatively to establish it as problematic and in need of solution, so it is worthy of research attention. As in Example [2], the study probes into the process of convenient editing, a common means for EAL researchers to shape their manuscripts. The experience of the convenient editors is appraised negatively through the use of an AFFECT resource "frustrating", which points out the problems associated with convenient editing. Hence, there is the need for research into the process to understand the problems and propose strategies to deal with them. The use of the GRADUATION resource "always", with the interplay of "not", downgrades this attitude. The missing of "always" ("to resolve uncertainties is not possible") would make the problem more severe. It is also worth mentioning here that the ENTERTAIN resource "can be", which belongs to the ENGAGEMENT framework, implies that the writers withhold the commitment to the proposition. This may also serve to downgrade the ATTITUDE.

[2] Moreover, several English teachers, those with and without editing experience, stated that editing colleague's texts can be frustrating [ATT: AFFECT], as meeting with authors to resolve uncertainties is not always [FORCE: INTEN] possible. (QUAL 07)

In many cases, the use of GRADUATION alone could be sufficient to imply the value of the research topic in certain aspects. In Example [3], the FORCE resources "numerous", "a wide range of" and "a growing number of" make reference to the large quantity and wide scope of studies conducted on the research topic ("lexical bundles"). Though not explicitly attitudinal, such a use of GRADUATION evokes a positive APPRECIATION of the topic area as a thriving field of research. Though not overtly stated, readers can easily infer the value of the topic from the great amount of interest it has already attracted. Similarly, in Example [4], the FORCE resource "back to the early 1990's" was used to refer to the long extent of time, evoking a positive APPRECIATION of the research topic because researchers in the field have a long-lasting interest in it.

[3] Numerous (FORCE: QUAN: amount) previous studies have investigated the relative frequencies of lexical bundles in a wide range of [FORCE: QUAN: extent] registers (e.g., Biber \& Conrad, 1999; Biber et al., 1999; Cortes, 2002). In addition, a growing number of [FORCE: QUAN: amount] studies have investigated differences in bundle use between native speakers (NSs) and non-native speakers (NNSs) (e.g. Ädel \& Erman, 2012; Chen \& Baker, 2010; DeCock, 2000; Römer, 2009). (QUAN 50)

[4] Work in energy-efficient database systems can be traced back to the early 1990's [GRADUATION: FORCE: extent]. (CNC 23) 
Overall, the evaluative meanings realized through the interplay of ATTITUDE and GRADUATION resources compel readers to align with the writers in their choice of the research topic. Further, the downgrading effect of ENGAGEMENT resource in Example [2] points to the potentially more fruitful finding we may derive to explore the interaction of all three sub-systems of APPRAISAL.

\subsection{1.b. Establishing a niche}

To establish a niche, writers need to argue that the existing knowledge of the topic is unresolved; hence there is a gap and demand for new knowledge. The purpose is usually achieved by evaluation of related studies to point out what is missing or needs to be addressed. Resources serving this purpose are often easy to identify as they are frequently accompanied by COUNTER resources from ENGAGEMENT framework, which carry a counter expectation connotation (e.g., however, while, even though). As in Example [5], the writers first presented three related studies on hardware compilation (“[3]”, "[4]”, "[5]") without explicitly appraise their value. The subsequent use of the COUNTER resource "however" dis-aligns readers with the value of the above studies. The limited value of these studies is further stressed by two negative APPRECIATION resources "give no support" and "hard", so as to argue a space for the writers to propose a new approach.

[5] PDTs for hardware compilation have been explored by researchers such as di Martino et al. [3] on data-parallel loops written in C source code, as part of a synthesis method from $\mathrm{C}$ to hardware. Compiler toolkits such as SUIF [4] and CoSy [5] allow multiple syntax patterns to be used together. However, these approaches give no support [ATT: APP: valuation] for including utility-directed transformations. Syntax pattern matching and transforming can also be done in tree rewriting systems such as TXL [11], but such general systems make it hard [ATT: APP: reaction] to incorporate hardware-specific knowledge into the transformations. (CNC 17)

Sometimes, the gap statement is made through positive acknowledgment of the contributions of related studies. However, the acknowledgment is always accompanied by COUNTER resources for the writers to shift their positive attitude at some point to establish the knowledge of the topic as unresolved. The positive acknowledgment can be achieved through GRADUATION resources alone without explicit ATTITUDE resources. As in Example [6], the GRADUATION resource "many" and its reference to the large number of studies on undergraduate student writing evokes a positive APPRECIATION of existing knowledge in the field as rich and prosperous. Nonetheless, the COUNTER resource "while" shifts the positive attitude to a negative one and the subsequent GRADUATION resource "few" evokes a negative APPRECIATION of the existing knowledge in the field as "inadequate" in providing a longitudinal picture, hence a space for the writers' own 
longitudinal case study. The other GRADUATION resource "relatively" serves to downgrade the negative APPRECIATION evoked through "few".

[6] While there have also been many [FORCE: QUAN: amount] studies focusing on undergraduate students (e.g. Green, 2013; Hirvela \& Du, 2013; Ivanič, 1998; Leki, 2007; Lillis, 2002; Li \& Casanave, 2012), as Belcher (2012) points out, relatively [FORCE: INTEN] few [FORCE: QUAN: amount] have used a longitudinal approach to explore undergraduate students' writing experiences and development across their content classes. (QUAL 01)

\subsection{1.c. Occupying a niche}

To occupy the niche, writers need to argue that their own research contributes to a new and more refined knowledge of the topic. The strategy to achieve this purpose is usually quite straightforward by explicit positive APPRECIATION. The positive APPRECIATION could be upgraded through GRADUATION. As in Example [7], a previous study of the writers' own was positively appraised in relation to other researchers' work through the use of an APPRECIATION resource "addresses the issues of". The contribution of the current study lies in that it "improves" the writers' previous work. The GRADUATION resource "significantly" upgrades the APPRECIATION.

[7] In [22], we proposed a geographic multicast routing protocol that addresses the issues of [ATT: APP: valuation] current hierarchical [6], [7], [8] and hybrid geographic routing protocols [20], [21]. This article significantly [FORCE: INTEN] improves [ATT: APP: valuation] our previous work [22]. (CNC 05)

Sometimes, the relevance of one's study to a specific context could be stressed through FOCUS. As in Example [8], the writer explicitly appraises her own study as "adding new knowledge" to the field of second language writing, aligning readers to a positive view of its contribution. This APPRECIATION is derived from the observation that the territory has been largely neglected in existing literature and positions the writer's own contribution in relation to the work of other disciplinary members. The FOCUS resource "particularly" upgrades the specificity of relevance and evokes a positive APPRECIATION of the study as highly relevant to the specific context of writing teacher education research. This may to some extent indicate the writers' strong alignment with the particular audience in that context.

[8] By exploring an unchartered territory of teachers' identity development, the study adds new knowledge to [ATT: APP: valuation] the field of second language writing, particularly [FOCUS: sharpen] in the realm of writing teacher education. (QUAL 18) 


\subsubsection{Variations of voice}

For the use of ATTITUDE, the results of quantitative analysis reveal that SLW writers deploy significantly more AFFECT and JUDGEMENT resources than their CNC counterparts. In the field of SLW, emotional feelings (AFFECT) and behaviors (JUDGEMENT) of participants can provide useful insights on the phenomenon under investigation. Therefore, many SLW studies probe into the feelings and behaviors of participants in order to construct an understanding of the research topic. As in Example [9], how students feel about the feedback they receive are encoded through two AFFECT resources "preferred". In this case, their positive feeling towards feedback on content and praise implies that these two kinds of feedback are more likely to yield positive pedagogical outcomes. The findings could thus provide useful implications on how to improve feedback practices to meet the needs of students. Similarly in Example [10], how L2 learners collaborate and learn in peer collaborations is encoded through two JUDGEMENT resources "able to", referring to the learners' increased capacity facilitated by interaction with peers. Their increased capacity implies that peer collaboration has a positive role to play in L2 learning, indicating the value of the research topic. However, in the field of CNC, human participants are usually not involved and the value of research depends on whether it contributes to the creation of better models or programs, which is related to APPRECIATION (as shown in Example[1], [5] and [7]).

[9] For instance, Cohen and Cavalcanti (1990) report on three small-scale studies in which most [FORCE: QUAN: amount] students preferred [ATT: AFFECT] feedback on content to error correction. Students would also have preferred [ATT: AFFECT] more praise for their writing, as teachers provided very [FORCE: INTEN] few [FORCE: QUAN: amount] positive comments, in particular [FOCUS: sharpen] to lower proficiency writers. (QUAL 15)

[10] The analysis of LREs confirms that, by pooling their individual resources, learners are quite often [FORCE: INTEN] able to [ATT: JUDGEMENT] reach correct solutions to their language-related problems and co-construct new language knowledge (e.g., Leeser, 2004; Storch, 2007; Swain \& Lapkin, 1998, 2002; Williams, 2001). Some studies have also provided evidence that this knowledge tends to be retained by the learner, who becomes "able to [ATT: JUDGEMENT] use the language of others (and the mental process that interaction has constructed)" (Swain \& Lapkin, 1998: 321). (QUAN 28)

For the use of GRADUATION, the results of quantitative analysis reveal that CNC writers deploy significantly more FORCE resources under the sub-category of "extent" than their SLW counterparts. As we examined more closely, the "extent" resources in CNC LRs are more frequently used to refer to proximity in time from the present. As in Example [11], a defect of the "pioneering" system in [40] is pointed out as "not convenient" for multicore 
systems. The "extent" resource "recently" suggests immediate relevance to the current study and evokes a positive APPRECIATION of the work in [5] and [6] as more updated from that in [40]. We can also see from Example [11] that research in the sub-discipline of CNC often builds upon previous works and makes new contributions by solving problems or eliminating defects, representing a cumulative nature of the knowledge in the field.

[11] Bressoud and Schneider [40] proposed the pioneering [ATT: APP: valuation] system with the lockstep method which depends upon architecture-specific implementation. Lockstep requires deterministic replay on the backup VM and is not convenient [ATT: APP: valuation] for multicore systems. Recently [FORCE: QUAN: extent], based on Xen live migration, Remus [5] and Kemari [6] provide an alternative solution. (CNC 06)

The results of the quantitative analysis also reveal that qualitative SLW writers make significantly more use of FOCUS resources under the sub-category of "sharpen" than their CNC counterparts, whereas no difference exists between the SLW groups or between CNC and quantitative SLW writers. As we examined more closely, such resources are mostly deployed to narrow down the specificity of the research context. As in Example [12], the "sharpen" resource "particularly" narrows down the context where the claim is valid for EFL learning with lower proficiency students. The more use of such "sharpen" resources in SLW LRs may suggest that there is a greater need for these writers to specify and tightly define the research context than their $\mathrm{CNC}$ counterparts.

[12] Therefore, teacher's intervention, whether direct or indirect, may be needed at all [FORCE: QUAN: amount] stages of the writing process particularly [FOCUS: sharpen] when dealing with EFL students at lower levels of proficiency. (QUAL 60)

\section{DISCUSSION}

\subsection{Common patterns of voice}

First, the results indicate a strong preference for all three groups of writers to express ATTITUDE as APPRECIATION rather than AFFECT or JUDGEMENT. This trend has been identified in research writing by students and in soft disciplines (Hood, 2004; Lee, 2015). The findings of our study suggest that this trend may be generalizable to RAs in both soft and hard disciplines. Compared to AFFECT and JUDGEMENT, which concerns with emotional feelings and assessment of human behaviors, APPRECIATION appraises the value of things (Martin \& White, 2005) and thus serves to objectify the attitude expressed. The preference for APPRECIATION could be interpreted as reflecting the normalized and 
objectified nature of research writing (Hood, 2004). Further, the study also discovered that among the three sub-categories of APPRECIATION, "valuation" is most frequently adopted by all groups of writers. The subcategory of "reaction", however, is more frequently identified in student dissertations (Hood, 2004). Therefore, the current finding of the preference to encode APPRECIATION as "valuation" in RAs may represent a distinct characteristic of published research writings.

Second, though not overtly attitudinal, GRADUATION resources identified across all LRs are frequently used to evoke positive or negative APPRECIATION. Again, the current findings suggest that this practice, which has been formerly detected in student dissertations and RAs in soft disciplines (Hood, 2004, 2005), may also be common in RAs in hard disciplines. For the frequency of GRADUATION resources, predominantly more FORCE than FOCUS resources are used across all LRs. The finding may suggest that FOCUS resources play limited role in serving the rhetorical purposes of research writing.

The study has also identified common patterns of ATTITUDE and GRADUATION resources and how they interplay to serve the rhetorical purposes of LR. This is an important and novel contribution considering that previous studies of LRs either lack a focus on linguistic features (Kwan et al., 2012); or did not offer generalizable findings due to the small sample size (Gil-Simon and Soler-Monreal, 2014). With reference to the established framework of APPRAISAL and studies that build upon it, the current study not only makes explicit a range of linguistic resources for writing LRs, but also accounts for the rhetorical effects created by the resources in a more systematic way. The identified patterns also show great similarities across the three groups of LRs. This finding may support the claim that members of the same discourse community do develop common conventions of writing practices (Swales, 1990). Nevertheless, as the three groups of academic writers under current exploration are further divided by disciplines and research paradigms, their writing practices also differ in meaningful ways.

\subsection{Variations of voice}

First, the two groups of SLW writers make significantly more use of AFFECT and JUDGEMENT resources than their CNC counterparts. This difference could be plausibly attributed to the subject matter of the larger discipline area of applied linguistics, which concerns "(a) language, (b) how it is learned and (c) how it is used, in order to achieve some purpose or solve some problems in the real world" (Schmitt \& Celce-Murcia, 2010: 1). The basis of such inquiries is human participants (language users, learners, teachers, etc.). As a result, the perceptions (AFFECT) and actions (JUDGEMENT) of the participants are an important focus of research in the discipline. On the contrary, the discipline of computer science deals with non-human subjects such as algorithmic process (Denning, 2005). So 
human feelings (AFFECT) and behavior (JUDGEMENT) are quite irrelevant in their research. This may suggest that the current finding about AFFECT and JUDGEMENT could offer more implication to the SLW writers rather than their CNC counterparts.

Second, CNC writers deploy significantly more "extent" resources than their SLW counterparts and most of the resources are used to refer to proximity in time from the present. This finding, together with similar observations in hard disciplines like physics (Bazerman, 1988), suggests that the cumulative and tightly structured nature of hard knowledge require writers to reference literature of recent vintage and immediate relevance to the current topic of inquiry (Hyland, 1999a, 1999b). The rhetorical effects created through "extent" resources, especially those referencing the proximity of time, can serve to upgrade relevance (as shown in Example [1] and [11]). This may be part of the reason for the significantly more frequent use of "extent" resources in the CNC LRs.

Qualitative SLW writers use significantly more "sharpen" resources than CNC writers to specify the research context. In soft disciplines, knowledge is more interpretive and subject to the influence of various contextual factors (Hyland, 1999b, 2008). Therefore, the validity of the claim needs to be established by specifying the context where it holds to be true in order to eliminate alternative interpretations (as shown in Example [8] and [12]). This may explain the significantly more frequent use of "sharpen" resources in the qualitative SLW LRs. However, the quantitative SLW writers do not differ in the use of "sharpen" resources from their CNC counterparts, which may be due to commonalities shared by the quantitative research paradigm and hard discipline in their epistemological beliefs.

Writers from the two sub-disciplines of CNC and SLW (hard vs. soft) demonstrate some significant differences in their writing practices. These differences may be attributed to the distinct characteristics of the two sub-disciplines. Although no significant difference was identified between qualitative and quantitative SLW writers in their use of ATTITUDE and GRADUATION resources, there are important differences in their deployment of ENGAGEMENT resources in LR (Zhang \& Cheung, 2017). These findings suggest that paradigmatic variation does not exist in all aspects of writing so that more research is in need to fully understand how paradigmatic writings vary and why.

\section{CONCLUSION}

The current study contributes to new knowledge of voice in RAs from APPRAISAL perspective by discovering meaningful patterns of voice realized through the interplay of ATTITUDE and GRADUATION resources. The identified patterns add to our knowledge of APPRAISAL on how it can be applied to understand writing conventions and expectations of different disciplines and research paradigms. Further, the current study adds to our 
knowledge of how to write effective LRs as it made explicit a set of linguistic resources that could be employed to achieve the rhetorical purposes of LR.

The findings of the study are two-fold. Firstly, the findings make explicit the potential linguistic resources and how they function in achieving the important rhetorical purposes of LRs (see Table 3 for a brief summary). Secondly, the findings reveal both common patterns and variations of voice in the LRs by three different groups of writers. This suggests that members of the academic discourse community do share similar writing conventions, but potential variations also exist between different disciplines (see Table 4 for a brief summary). The findings can offer practical guidance for novice writers who wish to publish their research in internationally refereed journals to become legitimate members of their discipline community. A key criterion for successful publication is for writers, novice and established alike, to conform to disciplinary writing conventions (Flowerdew, 2000). This, however, poses a challenge for novice research writers, especially those from EAL backgrounds who struggle with the difficulties of writing in an additional language. The findings can also offer useful pedagogical implications for EAP and ERPP instructors, particularly in the subdiscipline of SLW and CNC, in both L1 and L2 contexts. The finding can guide the efforts of material developers in producing writing manuals that provide systematic reference to EAL/ERPP writers in soft and hard disciplines alike.

Compared to other similar studies from APPRAISAL perspective, ours adopts a much larger corpus of 204 LRs from two sub-disciplines. The larger sample size enables a higherconfidence quantitative generalization of the findings within the two sub-disciplines. Nonetheless, the findings may not be generalizable to other sub-disciplines of computer science and applied linguistics. For a more comprehensive understanding of the writing conventions in the two fields, further studies need to be conducted with other sub-disciplines. Further, a former study (Gray, 2015) has uncovered complex linguistic variations that not only follow along disciplinary divisions, but also relate to other situational factors such as research purpose, the nature of research evidence, etc. Thus, future research may take in writing samples from a larger variety of disciplines and take into considerations their distinct situational characteristics for a more insightful understanding of linguistic variations in research writing.

The findings of the current study provide useful insights into the rhetorical effects research writers intend to create through the deployment of ATTITUDE and GRADUATION resources in achieving the goal of LR writing. Nevertheless, the study does not examine directly readers' construction of writer's voice in terms of whether the writers have succeeded in dis/aligning their readers with certain propositions. As previous research suggests that readers' construction of writer's voice has a role to play in the blind review process for publication (Matsuda \& Tardy, 2007), it would be productive for future studies to take it into consideration. Nevertheless, the insights on the readers' side were not completely precluded 
in our study. Since all the LRs in our corpus have reached publication, the writers have at least succeeded in aligning their most critical readers (i.e., gate-keeper journal reviewers) with the value of their research.

\section{\begin{tabular}{ll}
\hline Rhetorical purposes & Resources employed to achieve the purposes
\end{tabular}}

Establishing a territory

- To argue that the topic of study is of value and worthy of research attention
- $\quad$ ATTITUDE resources to positively appraise the research topic and point out its value (see Example [1])

- ATTITUDE resources to negatively appraise the research topic as problematic and point out the need for more research to resolve the problem (see Example [2])

- GRADUATION resources to grade the ATTITUDE resources in appraising the topic (see Examples [1] \& [2])

- GRADUATION resources to evoke APPRECIATION of the research topic (see Examples [3] \& [4])

Establishing a niche $\quad-\quad$ ATTITUDE resources to negatively appraise existing

- To argue that the existing knowledge of the topic is unresolved, hence a gap and demand for new knowledge studies in the topic area (see Example [5])

- GRADUATION resources to evoke negative APPRECIATION of existing studies (see Example [6])

- GRADUATION resources to grade the ATTITUDE resources in appraising existing studies (see Example [6])

- COUNTER resources from the ENGAGEMENT subsystem play an important role in coupling with ATTITUDE and GRADUATION resources to achieve the purpose (see Examples [5] \& [6])

\section{Occupying a niche}

- To argue that the study contributes to new and more refined knowledge of the topic
- APPRECIATION resources to positively appraise the contribution of the study to the topic area (see Examples [7] \& [8])

- GRADUATION resources to grade the APPRECIATION (see Example [7]) or to specify the relevance of the contribution (see Example [8])

- GRADUATION resources to evoke positive APPRECIATION of the study (see Example [8])

Table 3. A brief summary of the resources and how they serve the rhetorical purposes of LRs. 


\section{Common patterns}

Disciplinary variations

- APPRECIATION resources for appraising the value of things are more frequently used in LRs than AFFECT and JUDGEMENT resources for expressing emotional feelings and assessing human behavior

- The "valuation" sub-category of APPRECIATION is more frequently used than the other two sub-categories of "reaction" and "composition"

- GRADUATION resources, which are not overtly attitudinal, are frequently used to evoke positive or negative APPRECIATION of the research topic or existing studies in the field

- $\quad$ ATTITUDE and GRADUATION resources interplay in similar ways to serve the rhetorical purposes in LRs written by all three groups of writers (as summarized in Table 3)
- SLW writers use significantly more AFFECT and JUDGEMENT resources, because human participants are very important in applied linguistic research and how they feel (AFFECT) and behave (JUDGEMENT) can provide valuable insights on the phenomena under investigation (see Examples [2], [9] \& [10])

- $\mathrm{CNC}$ writers use significantly more "extent" (FORCE) resources to refer to the proximity in time (evoking a positive APPRECIATION of relevance), because the cumulative and tightly structured hard knowledge requires writers to reference literature of recent vintage and immediate relevance (see Examples [1] \& [11])

- SLW (qualitative) writers use significantly more "sharpen" (FOCUS) resources than $\mathrm{CNC}$ writers to specify the research context, because soft knowledge is more interpretive and subject to the influence of contextual factors (see Examples [8] \& [12])

Table 4. A brief summary of common patterns and disciplinary variations of voice in LRs.

\section{REFERENCES}

Bazerman, C. (1988). Shaping Written Knowledge. Madison, WI: University of Wisconsin Press.

Belcher, D. D. (2007). Seeking acceptance in an English-only research world. Journal of Second Language Writing, 16(1), 1-22.

Cao, F. \& Hu, G. (2014). Interactive metadiscourse in research articles: A comparative study of paradigmatic and disciplinary influences. Journal of Pragmatics, 66, 15-31.

Chang, P. \& Schleppegrell, M. (2011). Taking an effective authorial stance in academic writing: Making the linguistic resources explicit for L2 writers in the social sciences. Journal of English for Academic Purposes, 10, 140-151.

Cheung, Y. L. \& Low, T. H. (2017). Pre-university students' voice construction in argumentative essays. RELC Journal, 1-16. doi: 10.1177/0033688217716508

Cho, S. (2004). Challenges of entering discourse communities through publishing in English: Perspectives of Nonnative-Speaking Doctoral Students in the United States of America. Journal of Language, Identity and Education, 3(1), 47-72. 
Creswell, J. W. (2009). Research design: Qualitative, quantitative, and mixed methods approaches (3rd ed.). Thousand Oaks, CA: Sage.

Denning, P. J. (2005). Is Computer Science Science? Communication of the ACM, 48(4), 27-31.

Elbow, P. (1994). Introduction: About voice and writing. In P. Elbow (Ed.), Landmark Essays on Voice and Writing (pp. 11-47). Mahwah, NJ: Hermagoras Press.

Flowerdew, J. (2000). Discourse community, legitimate peripheral participation and the nonnativeEnglish-speaking scholar. TESOL Quarterly, 34(1), 127-150.

Flowerdew, J. \& Wang S. H. (2016). Author's editor revision to manuscripts published in international journals. Journal of Second Language Writing, 32, 39-52.

Gil-Salom, L. \& Soler-Monreal, C. (2014). Writers' positioning in literature reviews in English and Spanish Computing doctoral theses. Journal of English for Academic Purposes, 16, 23-39.

Guinda, C. S. \& Hyland, K. (2012). Introduction: A context-sensitive approach to stance and voice. In K. Hyland \& C. S. Guinda (Eds.), Stance and Voice in Written Academic Genres (pp. 1-11). United Kingdom: Palgrave Macmillan.

Gray, B. (2015). Linguistic variation in research articles: When discipline tells only part of the story. Amsterdam: John Benjamins.

Hood, S. (2004). Managing attitude in undergraduate academic writing: A focus on the introductions to research reports. In L. Ravelli \& R. Ellis (Eds.), Analysing academic writing: Contextualised frameworks (pp. 22-44). London: Continuum.

Hood, S. (2006). The persuasive power of prosodies: Radiating values in academic writing. Journal of English for Academic Purposes, 5, 37-49.

Hood, S. \& Martin, J. R. (2005). Invoking attitude: The play of graduation in appraising discourse. In J. Webster, C. Matthiessen \& R. Hasan (Eds.), Continuing discourse on language (pp. 740764). London: Equinox.

Humphrey, S. \& Hao, J. (2013). Deconstructing written genres in Undergraduate Biology. Linguistics and the Human Sciences, 7, 29-53.

Hyland, K. (1999a). Academic Attribution: Citation and the Construction of Disciplinary Knowledge. Applied Linguistics, 20(3), 341-367.

Hyland, K. (1999b). Disciplinary discourses: writer stance in research articles. In C. Candlin \& K. Hyland (Eds.), Writing: Texts, Processes and Practices (pp. 99-121). London: Longman.

Hyland, K. (2005). Stance and engagement: A model of interaction in academic discourse. Discourse Studies, 7(2), 173-192.

Hyland, K. (2008). Disciplinary voices: Interactions in research writing. English Text Construction, I(1), 5-22.

Hyland, K. (2012). Disciplinary Identities: Individuality and community in academic discourse. Cambridge: Cambridge University Press.

Ivanič, R. \& Camps, D. (2001). I am how I sound: Voice as self-representation in L2 writing. Journal of Second Language Writing, 10, 3-33.

Kwan, B. S. C., Chan, H. \& Lam, C. (2012). Evaluating prior scholarship in literature reviews of research articles: A comparative study of practices in two research paradigms. English for Specific Purposes, 31(3), 188-201.

(C) Servicio de Publicaciones. Universidad de Murcia. All rights reserved. IJES, vol. 18 (2), 2018, pp. 53-75 Print ISSN: 1578-7044; Online ISSN: 1989-6131 
Lancaster, Z. (2014). Exploring valued patterns of stance in upper-level student writing in the disciplines. Written Communication, 31(1), 25-57.

Lee, S. K. (2015). Evaluative stances in persuasive essays by undergraduate students: focusing on APPRECIATION resources. Text \& Talk, 35(1), 49-76.

Martin, J. R. \& White, P. R. R. (2005). The language of evaluation: Appraisal in English. New York, NY: Palgrave Macmillan.

Matsuda, P. K. \& Tardy, C. M. (2007). Voice in academic writing: The rhetorical construction of author identity in blind manuscript reviews. English for Specific Purposes, 26, 235-249.

McGrath, L. \& Kuteeva, M. (2012). Stance and engagement in pure mathematics research articles: Linking discourse features to disciplinary practices. English for Specific Purposes, 31(3), 161-173.

Miller, R. T., Mitchell, T. D. \& Pessoa, S. (2014). Valued voices - Students' use of Engagement in argumentative history writing. Linguistics and Education, 28, 107-120.

O'Donnell, M. (2011). UAM Corpus Tool (Version 3.2). Retrieved from http://www.wagsoft.com/CorpusTool/download.html

Ozturk, I. (2007). The textual organization of research article introduction in applied linguistics: Variability within a single discipline. English for Specific Purposes, 26, 25-38.

Ramanathan, V. \& Atkinson, D. (1999). Individualism, academic writing, and ESL writers. Journal of Second Language Writing, 8(1), 45-75.

Norbert, S. (2010). An Introduction to Applied Linguistics (2nd Ed.). Abingdon: Hodder Education.

Schimitt, N. \& Celce-Murcia M. (2010). An Overview of Applied Linguistics. In N. Schmitt (Eds.), An Introduction to Applied Linguistics (pp. 1-15). London: Hodder Education.

Swales, J. M. (1990). Genre analysis: English in academic and research settings. Cambridge: Cambridge University Press

Thompson, G. \& Hunston, S. (2000). Evaluation: An introduction. In S. Hunston \& G. Thompson (Eds.), Evaluation in text: Authorical stance and the construction of discourse (pp. 1-27). Oxford: Oxford University Press.

Uzuner, S. (2008). Multilingual scholars' participation in core/global academic communities: A literature review. Journal of English for Academic Purposes, 7, 250-263.

$\mathrm{Wu}, \mathrm{S} . \mathrm{M}$. (2007). The use of engagement resources in high- and low-rated undergraduate geography essays. Journal of English for Academic Purposes, 6, 254-271.

Zhang, W. Y. \& Cheung, Y. L. (2017). Understanding ENGAGEMENT resources in constructing voice in research articles in the fields of computer networks and communications and second language writing. The Asian ESP Journal, 13(2), 72-99. 